\title{
The Great Anatomy of Paolo Mascagni
}

What is probably the most spectacular book in The University of lowa Libraries is the exceedingly rare elephant-sized folio of handcolored anatomical plates known as the Anatomia universa of Paolo Mascagni, an eighteenth-century Italian physician and teacher. So rare is this work that it is little known even to specialists, though it may be said that Mascagni's atlas is to the field of human anatomy what the famous bird illustrations of Audubon are to the field of ornithology-most striking examples of applied art.

A gift from Dr. John Martin of Clarinda, Iowa, The University of Iowa's copy of this masterpiece is in pristine condition, having remained until recently in the possession of the same Italian family since its publication more than 150 years ago. Comprised of two sets of 44 plates, this "book" is so large it has never been bound.

Paolo Mascagni (1752-1815), the author of this work which is unique in all medical literature, was born in the small village of Castelleto in central Italy. ${ }^{1}$ Castelleto is near Siena in the province of Tuscany some 120 miles north of Rome. He received his early education at home and then was sent to the University of Siena where he studied philosophy, literature, physics, mathematics, and medicine.

Mascagni's scholarship, intelligence, and interest in the natural sciences were soon noticed by Pietro Tabarrani, professor of anatomy at Siena. Tabarrani became his mentor, and Mascagni was appointed prosector in anatomy at the university after receiving his medical degree in 1771. Tabarrani's health began to fail and, when he was forced to retire in 1774 because of blindness, Mascagni succeeded him as professor of anatomy. Mascagni felt so strongly that his professorial responsibilities lay in teaching and in advancing anatomical

1 Some authorities state that Mascagni was born in 1755 at Pomarance, which is near Volterra in the province of Tuscany. 
knowledge that he decided not to work in clinical medicine, preferring to devote himself entirely to teaching and research.

There was considerable political discord in Italy during the eighteenth century, and when the French occupied Tuscany in the late 1700s Mascagni became involved in politics and reluctantly served for several years as superintendent of the arts, sciences, and charitable institutions of Siena. This was a difficult and unhappy time in his life; he was in continuous conflict with the French over their incessant commandeering of personal and public property. When the Austrians regained control of the province, instead of being praised for his efforts on behalf of his fellow citizens, he was accused of collaborating with the French. He was arrested, spent several months in prison, and was eventually set free after a series of court battles.

Shortly thereafter the government appointed him professor of anatomy at the University of Pisa, possibly as atonement for having treated him so shabbily. He was soon offered professorships at Bologna, Padua, and Florence, and in 1801 he accepted a position at Florence. The authorities at Florence recognized his abilities and were so interested in attracting him that they combined the chairs of anatomy, physiology, and chemistry, doubled his salary, and gave him the responsibility of teaching anatomy to students of drawing, painting, and sculpture. Appreciative of the university's generosity, Mascagni decided to prepare a series of anatomical models that could be used by students of painting and sculpture. His objective was to depict the various systems of the human body through the medium of life-sized wax figures. He invested a considerable amount of his own money in this endeavor and, although he died before the project was finished, a number of these magnificent figures may still be seen in European museums today.

When Mascagni became prosector at Siena, Tabarrani had suggested that he concentrate his investigative efforts on the lymphatic system. In making this recommendation, Tabarrani showed a great deal of foresight, and research in this area was to bring Mascagni lasting fame and recognition. Although Frederik Ruysch (1638-1731) had tried to stimulate interest in the lymphatic system in Holland, the rest of Europe showed little interest in this area of the body. This may have been because of the influence of Albrecht Haller (1708-77), who had cast doubt on the entire lymphatic system by refuting the existence of lymphatic vessels in several parts of the body. The French scientific community was also concerned about research in this area and in 1784 the Academy of Sciences of Paris offered a prize for the best work demonstrating the lymphatic ves- 
sels. Mascagni continued his research and experimentation and submitted two substantial illustrated reports to the Parisian Academy. Unfortunately his work reached Paris after the deadline for acceptance of entries; nevertheless, members of the academy were so impressed that they awarded Mascagni a special prize. In order to protect the priority of his discoveries, he published this work in French and Italian in 1784 and the following year it was translated into German. ${ }^{2}$

Mascagni continued his studies of the lymphatic system, and in 1787 he published Vasorum lymphaticorum corporis humani historia et ichnographia. ${ }^{3}$ This important monograph contained the first systematic and definitive description of the lymphatic system in man. A large folio, it contains 41 brilliantly executed copperplates which faithfully represent the details of the lymphatic system. Mascagni has been credited with discovering some 50 percent of the lymphatic vessels, and it was this epochal work that opened the way for continued progress in our understanding of the anatomy and physiology of the human body.

In achieving such significant and accurate results, Mascagni performed numerous experiments, examined and repeated the observations of other investigators, and developed totally new methods or revised the techniques of other scientists in order to meet the needs of his research. It must be remembered that he was without the benefits of modern technology; yet he reached such a degree of perfection that modern researchers find it extremely difficult to duplicate his work. He used mercury as the contrast medium which he injected into the body's peripheral lymphatic networks by using a simple glass tube bent at a 90 -degree angle at one end and tapered to an extremely fine point. Mercury was poured into the other end of the glass tube and it quickly flowed through whatever part of the lymphatic system that was under study. By following the mercury injection with careful dissection, Mascagni obtained magnificent preparations which can still be seen and admired in the museum of the Institute of Normal Human Anatomy at the University of Siena.

Mascagni disproved the theory that the lymphatics originated from the terminal arteries and were continued in the veins through various very fine tubules. This ended the idea that there were arterial and venous lymphatics. After thoroughly examining the work of other

2 Paolo Mascagni, Prodrome d'un ouvrage sur le systeme des vaisseux lymphatiques (Siena: Vincent Pazzini Carli \& fils, 1784).

3 Paolo Mascagni, Vasorum lymphaticorum corporis humani historia et ichnographia (Siena: Ex typographia Pazzini Carli, 1787). 
anatomists and analyzing the results of his own investigations, he concluded that the lymphatic system originates from all the internal and external cavities and surfaces of the body and is directly related to the function of absorption. By means of colored injections he demonstrated that there is a link between the lymph and serous vessels. He also refuted the belief that there was an anastomosis between the lymphatics and the veins by showing that there is no connection between the two systems except at the point where the thoracic duct and the thoracic vein merge into the venous system. Mascagni discovered and described lymphatic vessels in regions of the body where they had not previously been known to exist. He determined that all the lymphatics pass through one or more lymph nodes during their course and provided excellent illustrations to document this fact. He did not limit himself to the study of the anatomy of the lymphatic system alone but also studied its physiology and pathology and emphasized the vital role it plays in maintaining the body's well-being.

After Mascagni's death in 1815, manuscripts and sketches for three additional works were found among his papers. The first, an anatomy for artists, was edited by Mascagni's brother, Bernardo, and his grandson, Aurelio, and published at Florence in 1816. ${ }^{4}$ Unfortunately these relatives both died soon after its publication, and a group of individuals interested in the welfare of Mascagni's family undertook the publication of the other two works. Responsibility for editing these last two works was given to Francesco Antommarchi (17801838 ), the physician who had been Mascagni's prosector and who had assisted in preparing the anatomy for artists. The second work. dealing with histological investigations on the anatomy of the human body, animals, and plants was published in two editions, one at Florence in 1819 and the other at Milan in $1821 . .^{5}$

Late in 1819 , while Antommarchi was on St. Helena acting as personal physician to Napoleon, differences between the group representing Mascagni's heirs and Antommarchi caused the group to institute a legal action which annulled their contract with Antommarchi. Their differences probably arose because the first two works had not sold very well. In 1822, rights to the third work, a large

4 Anatomia per uso degli studiosi di scultura e pittura, opera postuma di Paolo Mascagni (Florence: Dalla tipografia di Giovanni Marenigh, 1816).

5 Prodromo della grande anatomia; seconda opera postuma di P. Mascagni, posta in ordine e pubblicata a spese di une societd innominata da Francesco Antommarchi (Florence: Dalla tipog. Giov. Marenigh, 1819). The second edition, in two volumes, "riveduta ed illustrata da Tomasso Farnese," was published in Milan in 1821 under the imprint of Batelli e Fanfani. 
anatomy, were sold to Andrea Vaccá-Berlinghieri (1772-1826), Giacomo Barzellotti (1768-1839), and Giovanni Rosini (1776-1855)professors on the faculty at Pisa. It was these three individuals who prepared Mascagni's great anatomy-Anatomia universa, the splendid work which has recently been given to The University of Iowa Libraries. ${ }^{6}$

In the meantime, Antommarchi, who had taken three sets of plates with him to St. Helena to prepare them for publication, disregarded the court ruling and published his own edition of the plates at Paris between 1823 and 1826 without giving any credit to Mascagni. The 45 plates of the Antommarchi edition were lithographed and are technically inferior to the excellent copper engravings in the Anctomia universa. In addition, 24 of the figures that appear in Mascagni's anatomy are omitted from Antommarchi's work. ${ }^{7}$

The Anatomia universa is a comprehensive work of anatomy lacking only microscopic anatomy, histology, and the lymphatics of the skin. The skeleton, ligaments and tendons, fascia and muscles, viscera, cardiovascular system in special detail, the entire nervous system, the integument, the pregnant uterus and placenta, and the term fetus are shown life-size in color.

The three editors engaged Nicolao Capurro of Pisa to publish the book, and it was printed in a series of nine fascicules over nine years between 1823 and 1832. Each of the 44 plates in the copy owned by The University of Iowa Libraries is hand colored and accompanied by a duplicate outline plate which contains nomenclature for identifying the anatomical parts in the accompanying volume of text. The unbound plates in Iowa's copy are on unusually heavy paper in sheets measuring in excess of three and a half by two and a half feet. Plates showing the same plane of dissection may be so placed together that three of them depict the body of a life-size man. Many of the plates are signed by Antonio Serantoni (1780-1837), artist and engraver, while others have no signature at all and at least one plate names Joseph Canacci (fl. 1830) as engraver beside the artist, Serantoni. The plates were superbly engraved and the hand coloring by pen and brush was done so carefully and with such skill that the artist attained a degree of clarity and detail not to be found in any other of the

\footnotetext{
6 Paolo Mascagni. Anatomia universa XLIV tabulis aeneis juxta archetypum hominis adulti, accuratissime representata .. (Pisa: Apud Nicolaum Capurro. 1823-[32]).

7 Planches anatomiques du corps humain executées d'après les dimensions naturelles, accompagnées d'un texte explicatif par F. Antommarchi (Paris: C. de Lasteyrie, 1823-26).
} 


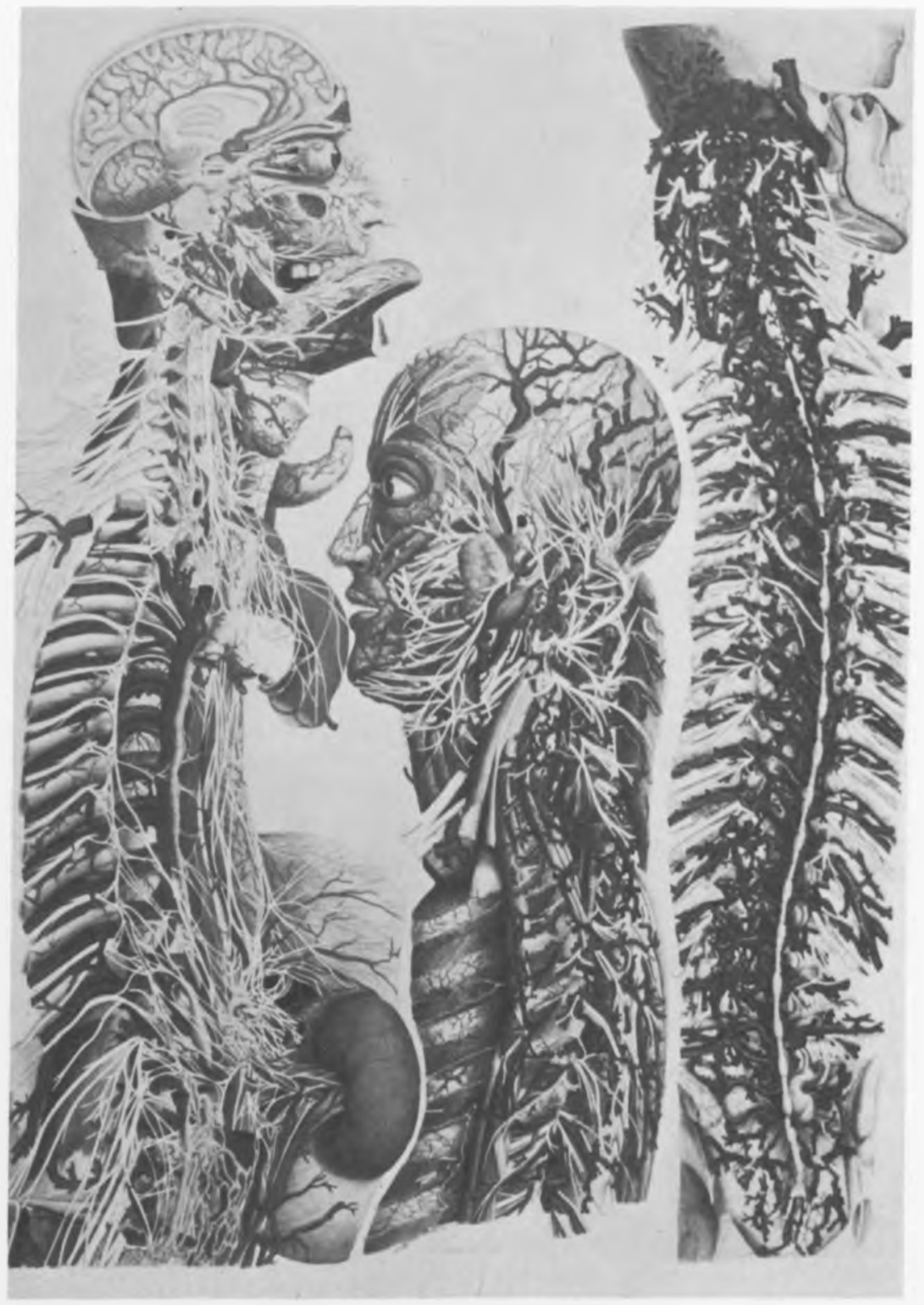

Tabula X from the Anatomia universa of Paolo Mascagni, showing three views of the upper body which depict aspects of the cervical, thoracic, lumbar, and sacral nerves. The original colored plate, with its brilliant blues and reds, is here vastly reduced. 


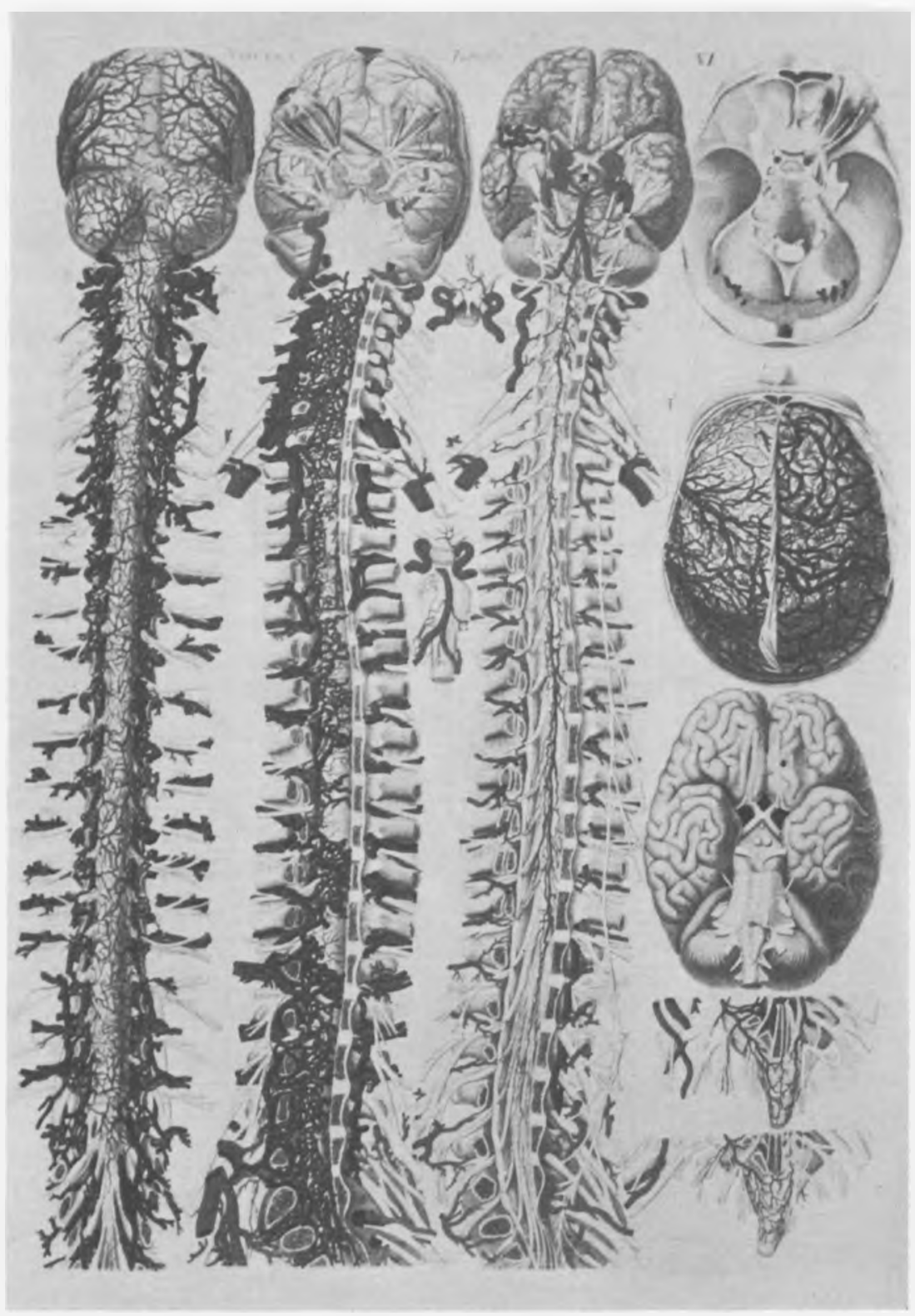

Another plate from Mascagni's great anatomy, table XI, showing anterior and posterior views of the brain and spinal cord. From the hand-colored copy in The University of Iowa Libraries. 
great anatomical atlases. The effect is often startling. In places one sees the structures as in three dimensions. According to the editors, Mascagni delayed publishing this magnificent work because he was hoping that it would be possible to make his plates by means of the color print alone.

Besides his serious and lasting commitment to anatomy and medicine, Mascagni had a number of other scientific interests which included mineralogy, botany, chemistry, and agriculture. He performed several important studies on the many small ponds in the countryside around Siena and wrote two books on the subject. Boric acid was abundant in their waters and he proposed a method for extracting the acid so that it could be converted into borax. This meant that Europe could produce its own borax and would no longer have to import large quantities from other parts of the world. Although this was eventually accomplished by others, Mascagni provided the initial impetus and the basic studies that made it possible. He explored many of the mines and caves of Tuscany and wrote detailed scientific reports on his findings. He also analyzed the waters of many mineral springs in central Italy and described their therapeutic properties.

Although he made a number of significant contributions to science, ${ }^{8}$ he will always be remembered for his work on the lymphatic system. Today indeed he is best known for his Vasorum lymphaticorum of 1787, but that work is overshadowed, as a work of art, by the later Anatomia universa, and it is bitter irony that his great posthumous work should be relatively unknown among medical historians. Its great cost and its rarity have undoubtedly contributed to its undeserved obscurity. The copy now at Iowa appears to be one of only three or four copies in the United States.

8 Information concerning Paolo Mascagni is the reverse of copious. Sources which have been consulted include Federigo Allodi. La evoluzione del pensiero anatomico nelle opere di Paolo Mascagni (Florence, 1955); R. Bertelli. "Paolo Mascagni (1752-1815)," Joumal of Cardiovascular Surgery 2 (1961), pp. 41421; Ludwig Choulant, History and bibliography of anatomic illustration, transl. and ed. M. Frank (Chicago, 1920); Carlo Fedeli, "Paolo Mascagni e la Università di Pisa (1799-1815)." Archeion; Archivo di storio della scienza 3 (1922), pp. 97-124; and Loris Premuda, Storia dell'iconografia anatomica (Milan, 1956). 